\title{
Reimagine Materials for Realizing SDG11: Sustainable Cities and Communities
}

\author{
Seeram Ramakrishna ${ }^{1} \cdot$ Rajan Jose $^{2}$ \\ Published online: 13 October 2021 \\ (c) The Author(s), under exclusive licence to Springer Nature Singapore Pte Ltd. 2021
}

Of all the frightening statistics recently on demands and sustainability, the most terrifying has been the one in the 6th report of the Intergovernmental Panel on Climate Change (IPCC); and the emergency warnings therein for the mankind to review activities leading to global warming cannot wait for actions and solutions (IPCC 2021). World leaders are now getting ready for the 26th UN Climate Change Conference of the Parties (COP26) in Glasgow, UK, during 31 October-12 November 2021. The COP26 is a clarion call to take urgent actions and rational targets to manage extreme weathers such as floods, heatwaves, rising seas, and superstorms through reduction of carbon emissions substantially by 2030 and net zero emissions by 2050 . On the backdrop of devastating COVID19 pandemic with no clear end in sight yet, climate action plans of countries are also distorted. Some countries use the opportunity to direct investments towards carbon neutral projects for future growth, some others diverted resources to fight the COVID19 while putting the carbon neutral projects on hold, while a few others are back peddling on their carbon neutral pledges primarily to secure economic growth at all costs. A recent landmark survey of ten thousand youths between 16 and 25 years from ten countries found that nearly $60 \%$ is "very worried" or "extremely worried," partly because governments are not doing enough to avoid a climate catastrophe, though they are relieved when the governments act (Hickman et al. 2021).

The UN predicts that $68 \%$ of the world population will live in urban areas by the year 2050, up from 55\% at present.

Seeram Ramakrishna

seeram@nus.edu.sg

Rajan Jose

rjose@ump.edu.my

1 Center for Nanotechnology and Sustainability, National University of Singapore, Singapore 117576, Singapore

2 Center of Advanced Intelligent Materials, Faculty of Industrial Sciences \& Technology, Universiti Malaysia Pahang, Gambang, Pahang, Malaysia
Cities contribute to $70 \%$ of the world economy with proportional energy consumption and consequent carbon emission. According to the World Bank, the cities will generate 3.4 billion tons of solid waste by 2050, up from 2 billion in 2016 . i.e., cities and communities are the most vulnerable and the largest contributors to the climate change, therefore, enough reasons to concentrate on the 11th UN SDG of "sustainable cities and communities". The SDG11 aims for affordable and sustainable housing and transport; mitigates extreme weathers and natural disasters, greening of public spaces, and resources efficiency; reduces the environmental impacts of cities; and enhances the resiliency of cities and communities. Undeniably, growing consumption is akin to urbanization and modern ways of living, thereby making cities as the largest contributors of carbon emission and environmental hazards. The solid material waste issue cannot be solved unless the waste is developed as resources, inevitably engaging the tools of materials circular economy. According to the Circularity Gap Report 2021 (Fraser et al. 2021), the world economy is only $8.6 \%$ circular, i.e., only $8.6 \%$ of the wastes are reused; adopting circular economy strategies is a way to cut global emissions by $39 \%$ and materials footprint by $28 \%$ by 2032 . On the other hand, creating new products from virgin materials generate over 22 billion tons of annual carbon emissions by the world economy, which can be reduced by circular materials economy strategies. Improved solid waste management strategies and increasing materials reuse from the current 8.6 to $17 \%$ is the most desirable way forward to control emissions.

For millennia, materials and chemicals are chosen for specific application based on their cost and ability to fulfil the functional property requirements. Availability and aesthetics influence their cost. Furthermore, the above discussions point towards emerging need for reimagining chemicals and materials based on lifecycle thinking so that they are purposely designed and made to be with low-carbon footprint and higher circularity and have no adverse impact on human health and well-being. These aspects 


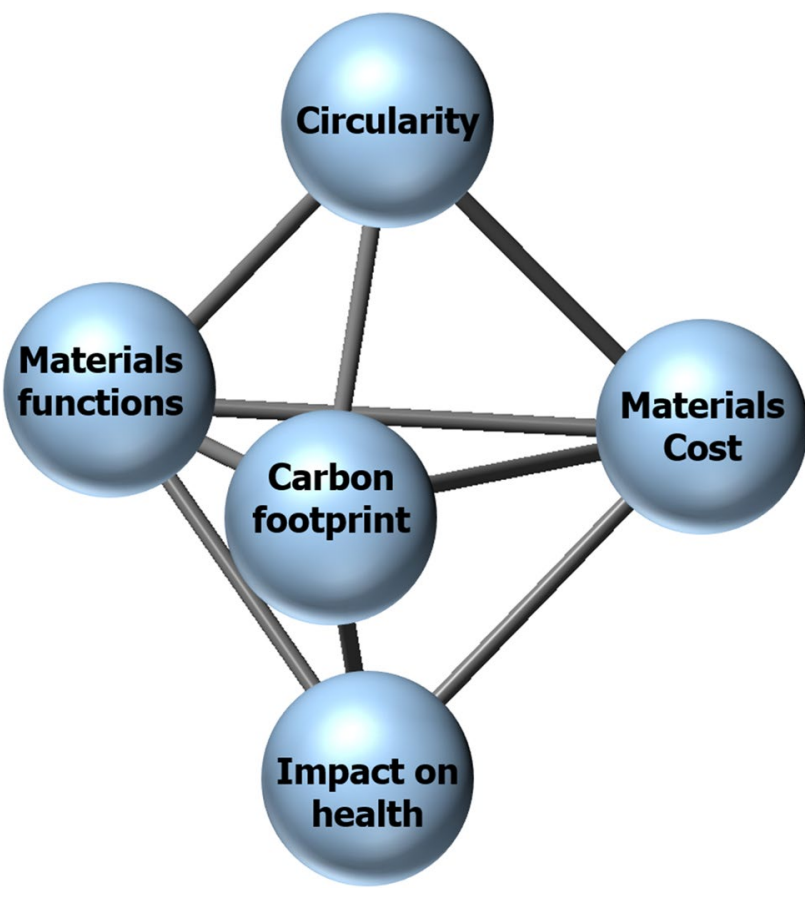

Fig. 1 Five tenants of reimagined materials for realizing the UN goal SDG11: sustainable cities and communities require reimagining chemicals and materials

also encompass several sustainability considerations such as harnessing materials from the renewable sources and local sources, selection of materials based on their lower embodied carbon and lower operational carbon footprints, resources efficiency of production processes supported by renewable energy, design out waste and pollution, design for recycling and upcycling, remanufacturing, and durability of materials. The five tenets of reimagined materials (see Fig. 1) or holistic materials circular economy enable carbon neutral transitions and advancements in diverse sectors of economy and human living. Future sustainable materials should have all these five characteristics: the materials should be (i) completely circular, i.e., every materials part in a used appliance could be recovered and fed back into production or sent back to nature for fertilization and reabsorption; (ii) material processing involves least or no carbon emission; (iii) the material should be able to deliver the targeted functionality; (iv) development of eco-friendly materials with no adverse health effects; and (v) lower cost such that the appliances could be affordable to the larger community. Intensive efforts are therefore required not only for extracting the elements in the electronic wastes (which is available at the rate of $>50$ tons per year) but also adding/enhancing functionalities of renewable materials using the lowest quantity of mined materials. Given the statistics that over 180 billion tons of materials are required by 2050 , up from 85 tons in 2015 (https://www.unep.org/news-andstories/press-release/worldwide-extraction-materials-tripl es-four-decades-intensifying), greenhouse gas emission cannot be controlled without strict measures and regulations on materials production. This reimagining is expected to create carbon neutral hydrogen and electron economies facilitating green energy, low-carbon materials for buildings and constructions and transportation infrastructure, carbon neutral data centres and digital technologies, zero-waste recycling of water, towards zero-waste solid waste management, carbon neutral agriculture, farming, biotechnology, food and nutrition, circular textiles and fashion, and carbon neutral appliances and mobile devices. They benefit from frontier scientific progress and novel innovations. Therefore, improving materials circular economy is an important way to contribute to the efforts of COP26.

\section{References}

Fraser M et al (2021) Circularity gap report, https://www.circularitygap.world/2021. Accessed 24 Sept 2021

Hickman C et al (2021) Preprint athttps://doi.org/10.2139/ssrn.39189 55

https://www.unep.org/news-and-stories/press-release/worldwide-extra ction-materials-triples-four-decades-intensifying (accessed on 25 Sept 2021)

IPCC (2021) Climate Change 2021: The physical science basis. https:// www.ipcc.ch/report/ar6/wg1/. Accessed on 24 Sept 2021

Publisher's Note Springer Nature remains neutral with regard to jurisdictional claims in published maps and institutional affiliations. 